\title{
Modeling of the Influence of Cutting Parameters on the Surface Roughness, Tool Wear and Cutting Force in Face Milling in Off-Line Process Control
}

\author{
Dražen Bajić* - Luka Celent - Sonja Jozić \\ University of Split, Faculty of Electrical Engineering, Mechanical Engineering and Naval Architecture, Croatia
}

\begin{abstract}
Off-line process control improves process efficiency. This paper examines the influence of three cutting parameters on surface roughness, tool wear and cutting force components in face milling as part of the off-line process control. The experiments were carried out in order to define a model for process planning. Cutting speed, feed per tooth and depth of cut were taken as influential factors. Two modeling methodologies, namely regression analysis and neural networks have been applied to experimentally determined data. Results obtained by the models have been compared. Both models have a relative prediction error below 10\%. The research has shown that when the training dataset is small neural network modeling methodologies are comparable with regression analysis methodology and can even offer better results, in which case an average relative error of 3.35\%. Advantages of off-line process control which utilizes process models by using these two modeling methodologies are explained in theory.
\end{abstract}

Keywords: off-line process control, surface roughness, cutting force, tool wear, regression analysis, radial basis function neural network

\section{INTRODUCTION}

Process control is the manipulation of process variables motivated by process regulation and process optimization. The adaptation of process variables, therefore has the purpose of reduction of production cost or cycle time. Usually, this is done through adjusting three impact factors: the cutting speed, the feed and the depth of cut and employing parameter estimation to adapt the model to changing process conditions. Within this category, Furness et al. regulated the torque in drilling [1].

Process control can be performed as an on-line or off-line process. Off-line process control refers to preliminary definition of process variables as part of a process planning stage. Selection of variables is usually based on a machine book or the operator's experience, therefore, computer aided process planning is a step forward and provides better results in production. Work carried out by Landers, Ulsoy and Furness concentrates on this subject [2]. Off-line process planning utilizes process models to select process variables based on experimental results like the influence of cutting parameters on surface roughness, tool wear and cutting force. The measured values are then used to determine the expected values according to an analytical model. Therefore, offline process control depends on the accuracy of the analytical model used. This is one of the drawbacks of this technique and an inability for error correction during the process. In this sophisticated technique the selection of modeling methodologies with their prediction errors has a great influence on the whole production. Lu [3] gives a detailed review of methodologies and practice on the prediction of surface profile and roughness in machining processes. Different modeling methodologies have already been applied for solving the problems of prediction in face milling, like design of experiment (DOE) and regression analysis (RA) as well as neural networks. For example, Bajić and Belajić [4] and Oktem et al. [5] used response surface methodology, while Ezugwu, Arthur and Hines [6] as well as Benardos and Vosniakos [7] used back propagation neural network approach. Neural networks were also used for an intelligent prediction of milling strategies particularly in commercially available $\mathrm{CAD} / \mathrm{CAM}$ systems [8]. Regarding tool wear estimation and tool breakage detection, Dong et al. [9] used the Bayesian multilayer perceptrons and Bayesian support vector machines for tool wear estimation, while Hsueh and Yang [10] used the support vector machines (SVM) methodology for tool breakage detection in modeling the face milling process precisely. Čuš and Župerl developed a system for monitoring tool condition in real time based on a neural decision system and Adaptive Neuro-Fuzzy Inference System (ANFIS) [11]. Parametric fuzzy membership functions based on neural network learning processes have been applied in the manufacturability assessment of free form machining [12].

Complex manufacturing and technological processes nowadays claim implementation of control systems using sophisticated mathematical and other methods for efficiency purposes. Thus, research is needed to get the mathematical approximations of machining processes and phenomena appearing as good as possible. In manufacturing engineers 
face two main practical problems. The first is to determine the values of the process parameters that will allow achievement of expected product quality and the second is to optimize manufacturing system performance with available resources. The decisions made by manufacturing engineers are based not only on their experience and expertise but also on the understanding of the machining principles and mathematical relations among influential parameters. The machining process is determined by the mutual relationship of the input values and its efficiency can be measured through output values. The great number of input values, as well as the fact that they have quantitative and qualitative nature contributes to the large expanse of possible interactions and their complexity. This model of the machining process was used in the research for this paper taking the parameters in italics and underlined among the input values as controlled ones and the same among the output values as measured ones (Fig. 1).

The aim of this research is to find mathematical models that relate the surface roughness, tool wear and the cutting force components with three cutting parameters, the cutting speed $\left(v_{c}\right)$, the feed per tooth $(f)$ and the depth of cut $\left(a_{p}\right)$, in face milling. In this research two different approaches have been used in order to get the mathematical models.

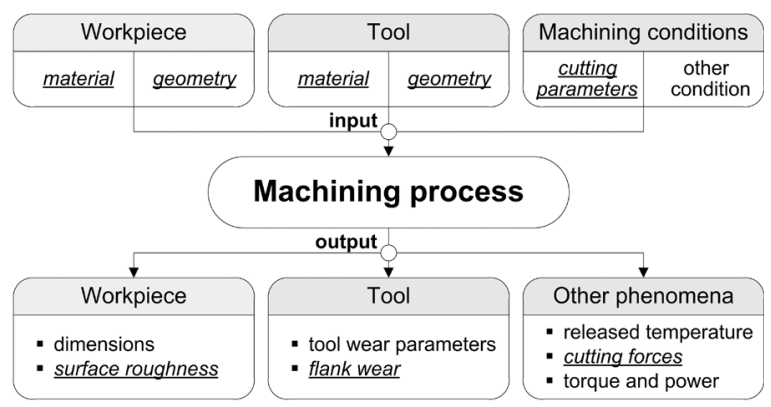

Fig. 1. Model of machining process

The first approach is a DOE together with an analysis of variance (ANOVA) and RA, and the second one is modeling by means of artificial neural networks (ANNs) [13] and [14]. In the past, the DOE approach was used to quantify the impact of various machining parameters on various output parameters, but nowadays ANNs has been proved as a method with great ability for mapping very complex and nonlinear systems. The milling process is an example of such a system and that justifies the usage of ANNs.

\section{PROCESS PHENOMENA THAT EMBODY ANALYTICAL BASIS FOR MACHINING PROCESS PLANNING}

The objective of machining operations is to produce parts with specified quality as productively as possible. Many phenomena that are important to this objective occur in machining operations, like surface roughness, tool wear and cutting force. Modeling of these three process phenomena by manipulation of cutting parameters provides important information for machining process planning as a part of the off-line process control.

Machining accuracy and capability of attaining the required surface quality is determined by selecting certain cutting parameters. Surface quality is one of the most specified customer requirements where a major indication of surface quality on the machined parts is surface roughness, Bernardos and Vosniakos provide a detailed review [14]. It is a widely used index of product quality and in most cases a technical requirement for mechanical products. Achieving the desired surface quality is of great importance for the functional behavior of a part. On the other hand, the process dependent nature of the surface roughness formation mechanism along with the numerous uncontrollable factors that influence pertinent phenomena, make it almost impossible to find a straightforward solution. Surface roughness is mainly the result of process parameters such as tool geometry and cutting conditions (feed per tooth, cutting speed, depth of cut), but in addition there is also a great number of factors influencing surface roughness (Fig. 2).

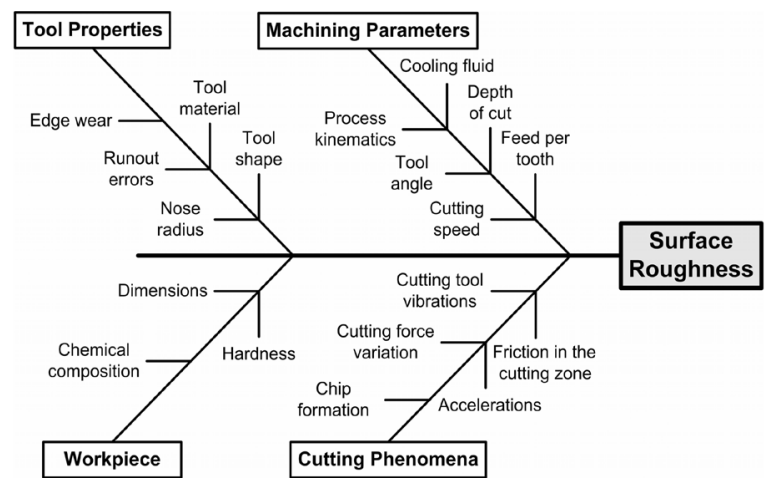

Fig. 2. Fishbone diagram with influential factors on machined surface roughness

Tool wear is a phenomenon that occurs on the contact area between the cutting tool, the workpiece and the chips [15]. Cutting tool wear is one of the key issues in all metal cutting processes, primarily 
because of its detrimental effect on the surface integrity of the machined component, and also it has a major influence in machining economics causing possible anomalies in final workpiece dimensions or eventual tool failure. The monitoring of tool wear is an important requirement for realizing automated manufacturing. Therefore, information about the state of tool wear is important to plan tool changes in order to avoid economic loses. Tool wear is a very complex phenomenon (Fig. 3) presented by Yan et al. [16], which leads to machine down time, product rejects and can also cause problems to personnel although this has not yet been well clarified. In face milling, tool wear becomes an additional parameter affecting surface quality of finished parts.

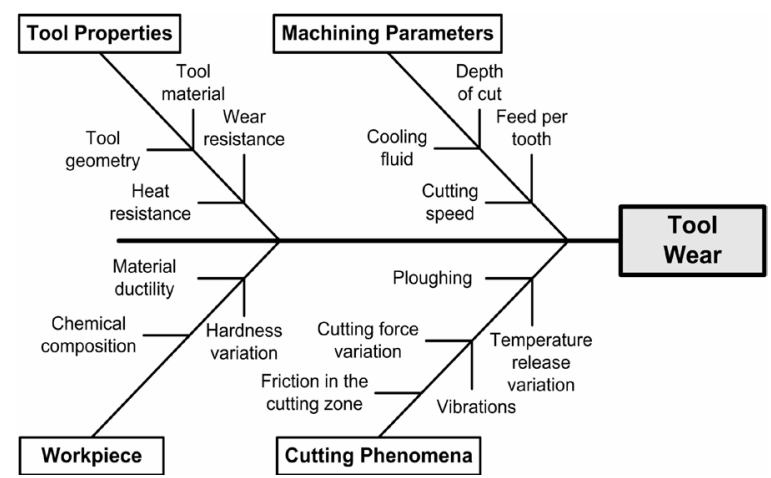

Fig. 3. Fishbone diagram with the parameters that affect tool wear

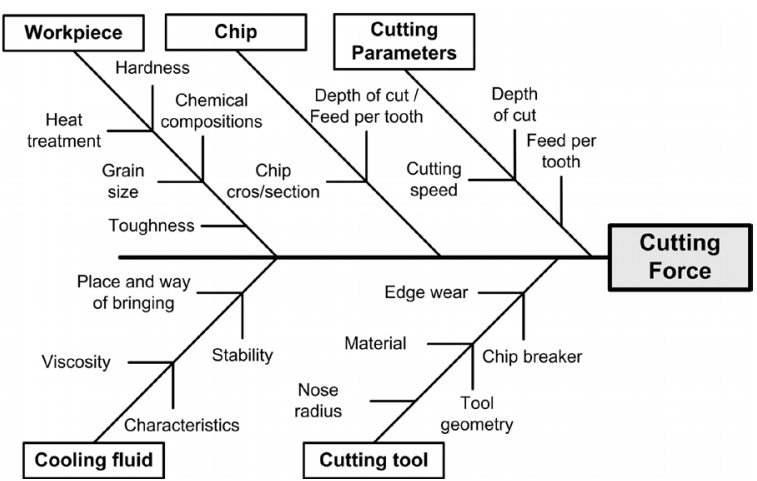

Fig. 4. Fishbone diagram with the parameters that affect cutting force

The surface formation mechanism during dynamic milling determines the cutting forces. The most regulated process variable in machining has been the cutting force, mainly for its reflection of process anomalies such as tool breakage and chatter [17]. In order to analyze the relation between the cutting forces and tool wear, cutting forces also need to be measured. The cutting forces developed during the milling operation are variable. Therefore, in practice the cutting forces are calculated according to the mean chip cross section in order to simplify the calculations. The researchers propose models that try to simulate the conditions during machining and establish cause and affect relationships between various factors that affect cutting force (Fig. 4) and the desired product characteristics.

Cutting force is one of the important physical variables that provides relevant process information in machining. Such information can be used to assist in understanding critical machining attributes such as machinability, tool wear fracture, machine tool chatter, machining accuracy and surface finish.

\section{DESIGN OF EXPERIMENT}

The planning of experiments means prior prediction of all influential factors and actions that will result from new knowledge utilizing the rational research. The experiments have been carried out using the factorial design of experiments. Milling is characterized by many factors, which directly or interconnectedly act on the course and outcome of an experiment. It is necessary to manage experiments with the statistical multifactor method due to the statistical character of a machining process. In this work, the design of experiments was achieved by the rotatable central composite design (RCCD). In the experimental research, modeling and adaptive control of multifactor processes the RCCD of experiments is very often used because it offers the possibility of optimization [18]. The RCCD models the response using the empirical second-order polynomial:

$$
y=b_{0}+\sum_{i=0}^{k} b_{i} \cdot X_{i}+\sum_{1 \leq i<j}^{k} b_{i j} \cdot X_{i} \cdot X_{j}+\sum_{i=1}^{k} b_{i i} \cdot X_{i}^{2}
$$

where $b_{0}, b_{i}, b_{i j}, b_{i i}$ are regression coefficients, and $X_{i}$, $X_{j}$ are the coded values of input parameters.

The required number of experimental points for RCCD is determined:

$$
N=2^{k}+2 k+n_{0}=n_{k}+n_{\alpha}+n_{0},
$$

where $k$ is the number of parameters, $n_{0}$ is the repeated design number on the average level, and $n_{\alpha}$ is the design number on central axes.

RCCD of experiment demands a total of 20 observed conditions (experiments), 8 experiments ( 3 factors on two levels, $2^{3}$ ), 6 experiments on the central axes and 6 experiments on the average level. The theory of the design of experiments and mathematicalstatistical analyses use coded values of input factors 
of the milling process. The coded values of three independent input factors have values on five levels, Table 1.

Table 1. Physical and coded values of input factors

\begin{tabular}{|c|c|c|c|c|c|c|}
\hline $\begin{array}{l}\text { Coded } \\
\text { values }\end{array}$ & Levels & -1.682 & -1 & 0 & 1 & 1.682 \\
\hline \multirow{3}{*}{ 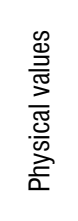 } & $\begin{array}{l}X_{1}=v_{c} \\
{[\mathrm{~m} / \mathrm{min}]}\end{array}$ & 113.18 & 120 & 130 & 140 & 146.82 \\
\hline & $\begin{array}{c}X_{2}=a_{p} \\
{[\mathrm{~mm}]}\end{array}$ & 0.83 & 1.00 & 1.25 & 1.50 & 1.67 \\
\hline & $\begin{array}{c}X_{3}=f \\
{[\mathrm{~mm} / \text { tooth }]}\end{array}$ & 0.07 & 0.10 & 0.15 & 0.20 & 0.23 \\
\hline
\end{tabular}

\section{NEURAL NETWORK MODELING}

ANNs are non-linear mapping systems that consist of simple processors, called neurons, linked by weighted interconnections. Using a large amount of data out of which they build knowledge bases, ANNs establish the analytical model to solve the problems of prediction, decision-making and diagnosis. Fitting neural network parameters as a foreground learning task, allows the mapping of given input to known output values. The learning data set usually consists of input $n$-dimensional vectors $x$ and corresponding output $m$-dimensional vectors $y$. Learning neural network parameters can be considered as a problem of approximation or interpolation of the hyper-plane through the given learning data. After the learning has finished, computation of responses of the neural network involves computation of values of the approximated hyper-plane for a given input vector. Approximation theory is employed with problem approximation or interpolation of the continuity of multi-variable function $f(x)$ by means of approximate function $F(w, x)$ with an exact determined number of parameters $w$, where $w$ are real vectors:

$$
x=\left[x_{1}, x_{2}, \ldots, x_{n}\right]^{T}, \quad w=\left[w_{1}, w_{2}, \ldots, w_{n}\right]^{T}
$$

To fulfill the approximation of the continual nonlinear multi-variable functions well enough, it is required to solve two key problems:

1. The proper selection of the approximate function $F(w, x)$ that can efficiently approximate the given continuity of multivariable function $f(x)$. This is known as the representation problem.

2. Defining an algorithm in order to compute optimal parameter $w$, according to optimal criteria given in advance.
Interpolation with a radial basis function (RBF) is one of the most successful methods for solving the problem of continuity multi-variable functions. With an implementation of the radial based function, the solution of the interpolation problem is given in the following form:

$$
F(x)=\sum_{i=1}^{N} c_{i} \cdot h\left(\left\|x-x_{i}\right\|\right)
$$

where $x n$-dimensional input vectors, are regression coefficients, $x_{i} n$-dimensional vectors of position of point of learning data set, $c_{i}$ unknown interpolation coefficient, $h($.$) radial basis function, \|$.$\| Euclidean$ distance in multi-dimensional real space $\mathrm{R}_{\mathrm{n}}$, and $N$ is the number of interpolation points.

In the classical approach to RBF network implementation, the Gaussian function is preferred as a radial basis function.

The researchers have shown that, in reality, where the learning data set is ordinarily weighted with some noise, better results have been achieved by approximation rather than interpolation. Namely, it is expected to filter the noise by means of approximation, in contrast to interpolation where the hyper-plane passes exactly through all points of the learning data set. It is a logical question whether it is necessary to compute the distance of all $N$ points of the learning data set. Broomhead and Lowe [19] suggested selecting $K$ points (called the center), where $K<N$. Now Eq. (3) has the form:

$$
F(x)=\sum_{j=1}^{K} c_{j} \cdot h\left(\left\|x-t_{j}\right\|\right)
$$

where $t_{i} n$-dimensional vectors of the center of the radial basis function.

With approximation, the number of center $\mathrm{K}$ is less than the number of points $N$. The number and the position of the centers of the neurons of the hidden layers has been determined in the learning procedure. Then, Euclidean distances of the input vector have been computed for the neurons of the hidden layer $h$ ( $\left.\left\|x_{i}-t_{j}\right\|\right)$, where is $i=1, \ldots, N(N$ is the index of the input vector), $j=1, \ldots, K$ ( $K$ is the index of the neuron of the hidden layer). In this way, rectangular matrix $(N \times X)$ of the values of the hidden layer has been computed $(H)_{i j}=h\left(\left\|x_{i}-t_{j}\right\|\right)$.

The implementation of $N$ interpolation conditions leads to a predeterminated system of $N$ linear equations with $K$ unknown terms (weighted vector is $\left.c=\left[\begin{array}{llll}c_{1} & c_{2} & \ldots & c_{K}\end{array}\right]^{T}\right)$. In this case, the optimal solution, according to the minimal square criterion, has been 
achieved with a pseudo inversion of the matrix $H$. The solution represents the approximation of the multivariable function.

The main advantages of the RBF model are its simplicity and the ease of implementation. The learning and generalization abilities of these networks are extremely good. The RBF model which is used in this study, for approximation of the two-variable function $f(x), x=\left[\begin{array}{ll}x_{1} & x_{2}\end{array}\right]^{\mathrm{T}}$, is shown in Fig. 5. The construction of the radial basis function network involves three entirely different layers. The input layer is composed of three neurons. The output layer has one neuron. The number of neurons of the hidden layer is equal to the number of the $K$ centers.

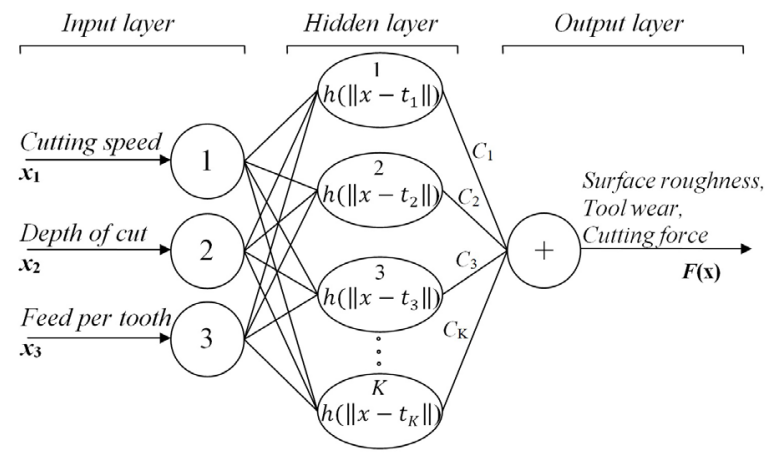

Fig. 5. RBF neural network model

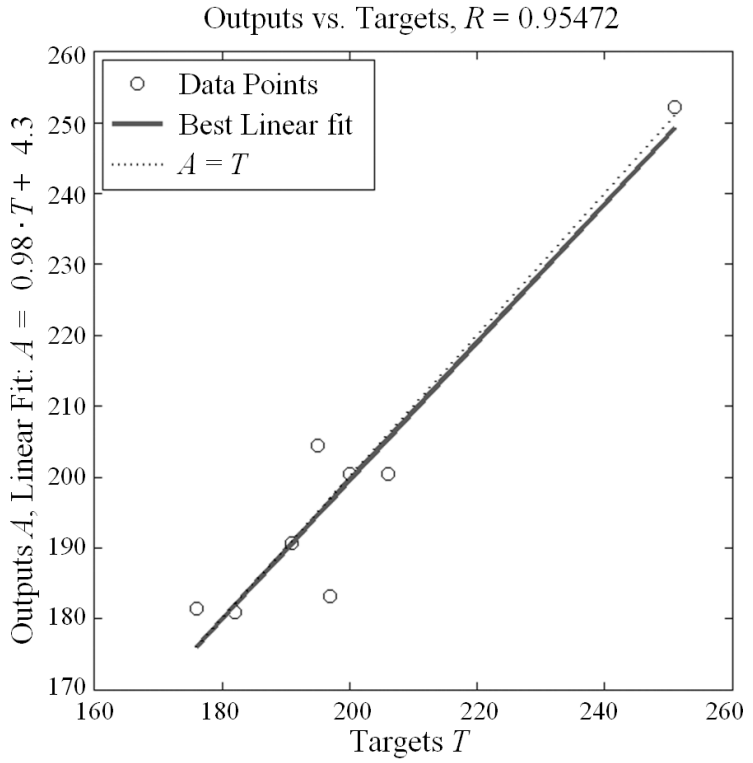

Fig. 6. Results of testing for generalization ability of Setup 3

The same network architecture has been used for modeling each of five physical relations separately. The network setups are named as:
- Setup 1 - relates cutting parameters and surface roughness,

- Setup 2 - relates cutting parameters and tool wear,

- Setup 3 - relates cutting parameters and $F x$ component of cutting force,

- Setup 4 - relates cutting parameters and Fy component of cutting force,

- Setup 5 - relates cutting parameters and $F z$ component of cutting force.

Results of testing, in the form of regression analysis, for Setup 1 is shown in Fig. 6. $R$ is a measure of agreement between the outputs and targets, and the aim is to get an $R$-value close or equal to 1 . In the example in Fig. 6, it is 0.9547 and that indicates that the model is representative and with the same, $95.47 \%$ of deviations were interpreted.

\section{EXPERIMENTAL SETTINGS}

The type of machine tool used for the milling test was machining center VC 560 manufactured by Spinner. The test sample used in experiments was made of steel $42 \mathrm{CrMo} 4$ with dimensions $110 \times 220 \times 100 \mathrm{~mm}$. The face milling experiments were executed by a tool CoroMill 390 with three TiN coated inserts, produced by Sandvik.

Table 2. Measured experimental data

\begin{tabular}{cccccc}
\hline $\begin{array}{c}\text { Exp. } \\
\text { Num. }\end{array}$ & $\begin{array}{c}R a \\
{[\mu \mathrm{m}]}\end{array}$ & $\begin{array}{c}V B_{\max } \\
{[\mu \mathrm{m}]}\end{array}$ & $\begin{array}{c}F x \\
{[\mathrm{~N}]}\end{array}$ & $\begin{array}{c}F y \\
{[\mathrm{~N}]}\end{array}$ & $\begin{array}{c}F z \\
{[\mathrm{~N}]}\end{array}$ \\
\hline 1 & 0.59 & 30 & 196 & 135 & 36 \\
\hline 2 & 0.53 & 70 & 157 & 132 & 40 \\
\hline 3 & 1.45 & 35 & 290 & 150 & 48 \\
\hline 4 & 1.18 & 80 & 235 & 145 & 51 \\
\hline 5 & 0.61 & 45 & 192 & 135 & 36 \\
\hline 6 & 0.70 & 70 & 198 & 131 & 38 \\
\hline 7 & 1.55 & 50 & 316 & 192 & 56 \\
\hline 8 & 1.19 & 72 & 261 & 168 & 46 \\
\hline 9 & 0.73 & 35 & 205 & 165 & 45 \\
\hline 10 & 0.50 & 90 & 185 & 142 & 39 \\
\hline 11 & 0.48 & 43 & 160 & 103 & 33 \\
\hline 12 & 1.82 & 55 & 308 & 175 & 54 \\
\hline 13 & 0.85 & 45 & 166 & 134 & 40 \\
\hline 14 & 0.92 & 60 & 250 & 180 & 45 \\
\hline 15 & 0.84 & 50 & 190 & 140 & 41 \\
\hline 16 & 0.79 & 50 & 188 & 142 & 42 \\
\hline 17 & 0.85 & 55 & 190 & 141 & 42 \\
\hline 18 & 0.81 & 52 & 192 & 139 & 43 \\
\hline 19 & 0.86 & 50 & 189 & 141 & 42 \\
\hline 20 & 0.87 & 50 & 187 & 140 & 40 \\
\hline & & & & &
\end{tabular}


The cutting forces were measured by utilizing a Kistler dynamometer type 9271A. The dynamometer signals were then processed via charge amplifiers and an A/D converter to a computer. Tool wear and workpiece surface roughness were periodically measured, maximum flank wear land width $V B_{\max }$ of cutting tools by optical microscopy (10 times increase), and average surface roughness $R a$ of machined workpieces by a Surftest SJ-301, produced by Mitutoyo. The measurements of surface roughness were taken at five predetermined different places on the sample. During the process of measuring, the cut-off length was taken as $0.8 \mathrm{~mm}$ and the sampling length as $5.6 \mathrm{~mm}$.

Before the measurements were carried out all the measuring instruments were calibrated. All experiments were carried out without cooling and lubrication agents. Altogether 33 experiments were conducted. Twenty experiments were conducted in order to allow performance of ANOVA and regression analysis (Table 2), and an additional 13 experiments to obtain additional data for performing RBF modeling and verification of both models (Table 3). For those experiments, the values of the cutting parameters were randomly chosen within the range. Altogether, 28 data pairs have been chosen for the procedure of training and testing the RBF model. Five experiments were discarded because RCCD demands six repetitions at the center point. Before the training and testing, all input and output data have been scaled to be within the interval -0.9 and 0.9. After the training, models were tested for their generalization ability. Testing was performed with the data that had not been used in the training process. In order to conduct training and testing of the neural network models, a neural network toolbox embedded in MATLAB [20] was used. Eight data pairs, randomly selected and marked with an asterisk $(*)$, were utilized for the validation of both RA and ANN modeling.

\section{ANALYSIS OF RESULTS \\ OF BOTH RA AND NEURAL NETWORKS SIMULATION}

The measured values of surface roughness, tool wear and cutting force components, obtained by 20 experiments are presented in Table 2. The ANOVA and RA have been performed using program package "Design Expert 6".

By applying regression analysis the coefficients of regression, multi-regression factors, standard false evaluation and the value of the $t$-test have been assessed. After omitting insignificant factors the mathematical models for surface roughness $R a$, tool wear $V B_{\max }$ and the components of cutting force $F x$, $F y, F z$, were obtained as follows:

$$
\begin{aligned}
R_{a}=- & 10.58+0.17 \cdot v_{c}+14.25 \cdot f-6.04 \cdot 10^{-4} \cdot v_{c}^{2}+ \\
+ & 52.34 \cdot f^{2}-0.16 \cdot v_{c} \cdot f, \\
V B_{\max }= & 0.65-7.2 \cdot 10^{-3} \cdot v_{c}-0.13 \cdot f+0.2 \cdot a_{p}+ \\
& +4.24 \cdot 10^{-5} \cdot v_{c}^{2}-1.72 \cdot 10^{-3} \cdot v_{c} \cdot a_{p}, \\
F_{x}= & 1526.9-15.7 \cdot v_{c}+882.3 \cdot f-654.2 \cdot a_{p}+ \\
& +7743.04 \cdot f^{2}+162.6 \cdot a_{p}^{2}, \\
F_{y}= & 796.9-9.4 \cdot v_{c}+357.7 \cdot f-144.9 \cdot a_{p}+ \\
& +0.04 \cdot v_{c}^{2}+86.9 \cdot a_{p}^{2}+660 \cdot f \cdot a_{p}, \\
F_{z}=- & 63.81+379.5 \cdot f-3.25 \cdot v_{c} \cdot f-0.75 \cdot v_{c} \cdot a_{p} .
\end{aligned}
$$

The squares of regression coefficient $\left(r^{2}\right)$ for $F x$, $F y, F z, R a$ and $V B_{\max }$ are $0.9468,0.9607,0.9402$, 0.9829 and 0.9908 respectively.

Table 3. Additional measured experimental data

\begin{tabular}{cccccc}
\hline $\begin{array}{c}\text { Exp. } \\
\text { Num. }\end{array}$ & $\begin{array}{c}R a \\
{[\mu \mathrm{m}]}\end{array}$ & $\begin{array}{c}V B_{\max } \\
{[\mu \mathrm{m}]}\end{array}$ & $\begin{array}{c}F x \\
{[\mathrm{~N}]}\end{array}$ & $\begin{array}{c}F y \\
{[\mathrm{~N}]}\end{array}$ & $\begin{array}{c}F z \\
{[\mathrm{~N}]}\end{array}$ \\
\hline $21^{*}$ & 0.79 & 58 & 176 & 136 & 42 \\
\hline 22 & 0.86 & 59 & 193 & 149 & 45 \\
\hline $23^{*}$ & 0.82 & 52 & 200 & 148 & 45 \\
\hline 24 & 1.71 & 54 & 250 & 170 & 51 \\
\hline 25 & 0.60 & 53 & 165 & 142 & 40 \\
\hline 26 & 1.34 & 64 & 270 & 185 & 58 \\
\hline $27^{*}$ & 1.55 & 55 & 206 & 143 & 48 \\
\hline $28^{*}$ & 0.64 & 41 & 182 & 135 & 41 \\
\hline 29 & 1.61 & 55 & 221 & 146 & 56 \\
\hline $30^{*}$ & 1.46 & 64 & 195 & 149 & 45 \\
\hline $31^{*}$ & 0.71 & 61 & 191 & 134 & 41 \\
\hline $32^{*}$ & 0.65 & 40 & 197 & 143 & 42 \\
\hline $33^{*}$ & 1.60 & 57 & 251 & 171 & 52 \\
\hline & & & & &
\end{tabular}

Table 3 shows 13 additional measured experimental data. Data marked with an asterisk (*) were not used either in the network training or in the regression analysis. These data were utilized for the validation of both regression analysis and ANN modeling. Table 4 shows the values of surface roughness, tool wear and cutting force components obtained from both types of modeling, i.e. from the regression equations and from the simulation of neural network setups.

Observing the changes of $R a$ and $V B_{\max }$ with increase of cutting speed, the connection between the two phenomena is established (Figs. 7 and 8 ). Therefore, cutting speed is closely related to 
a)

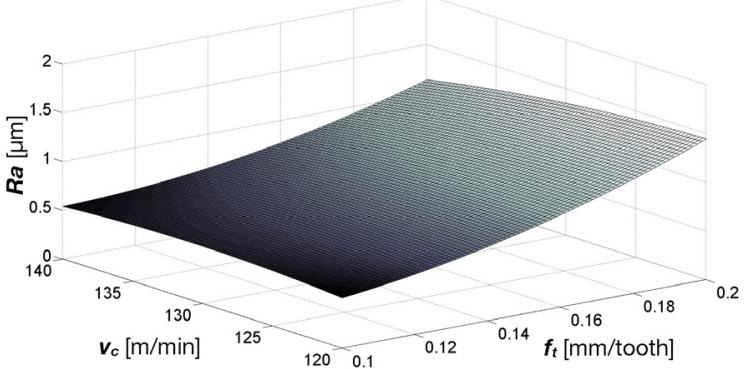

b)

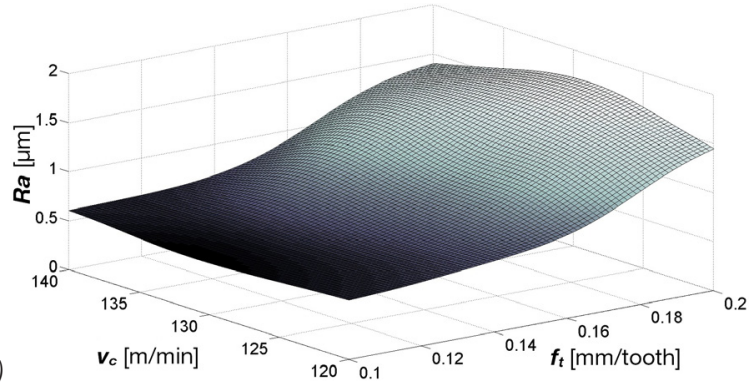

Fig. 7. Response surface for surface roughness as a function of cutting speed and feed per tooth obtained from RA (a) and RBF (b); for constant depth of cut of $1.25 \mathrm{~mm}$
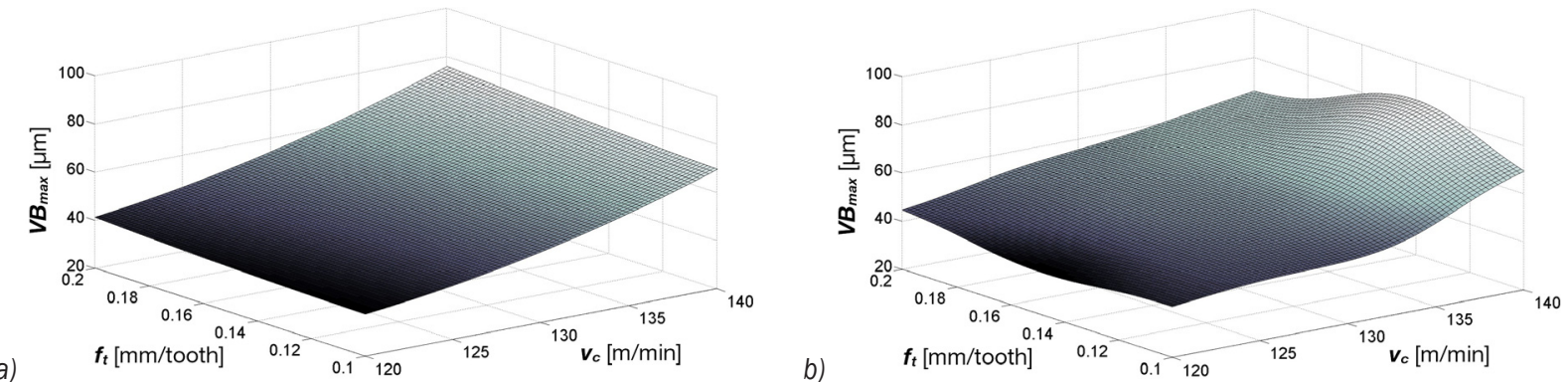

Fig. 8. Response surface for tool wear as a function of cutting speed and feed per tooth obtained from RA (a) and RBF (b); for constant depth of cut of $1.25 \mathrm{~mm}$
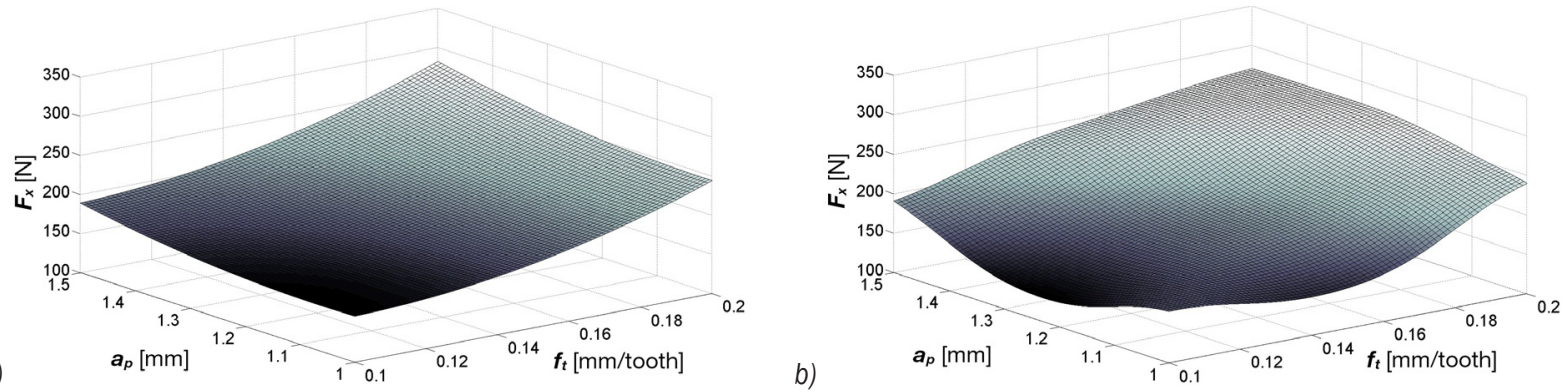

Fig. 9. Response surface for Fx component of cutting force as a function of depth of cut and feed per tooth obtained from RA (a) and RBF (b); for constant cutting speed of $130 \mathrm{~m} / \mathrm{min}$
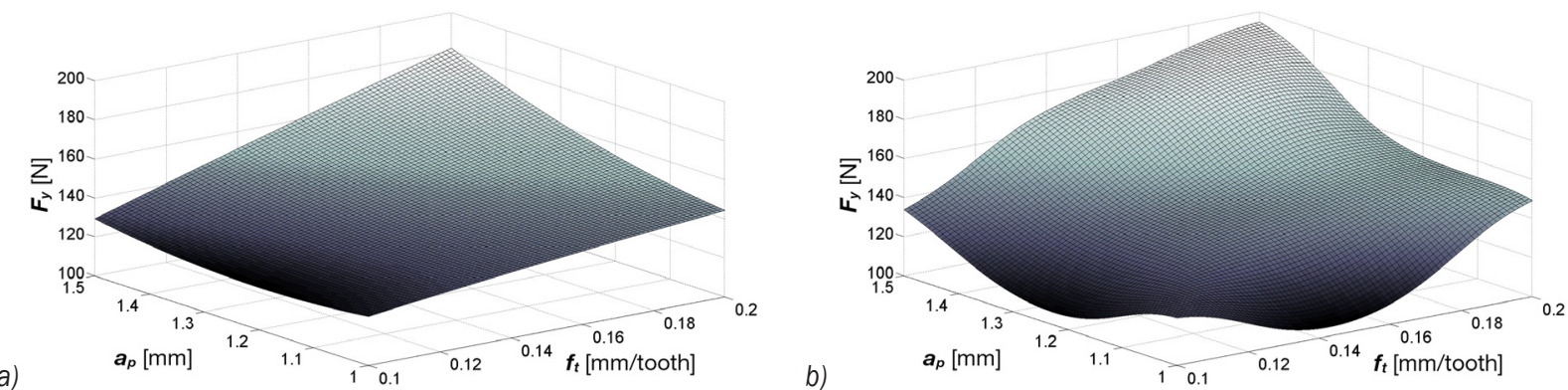

Fig. 10. Response surface for Fy component of cutting force as a function of depth of cut and feed per tooth obtained from RA (a) and RBF (b); for constant cutting speed of $130 \mathrm{~m} / \mathrm{min}$

emergence of built-up edge (BUE) and that implies its effect on machined surface roughness. By increasing the cutting speed the influence of BUE is reduced, and it also increases surface quality, but exaggeration in the increase of cutting speed does not influence the further reduction of surface roughness because tool wear is simultaneously increased and it keeps roughness nearly constant. Feed per tooth is directly 
a)

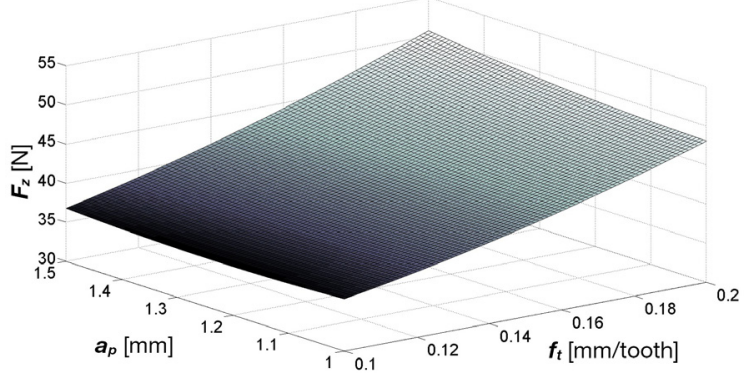

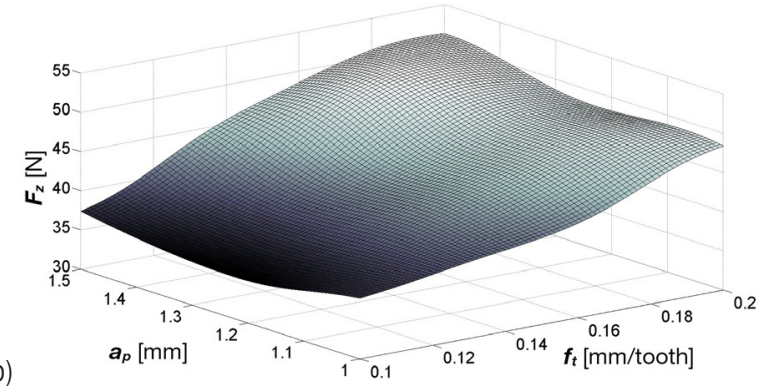

b)

Fig. 11. Response surface for Fz component of cutting force as a function of depth of cut and feed per tooth obtained from RA (a) and RBF (b); for constant cutting speed of $130 \mathrm{~m} / \mathrm{min}$

proportional to surface roughness with a power of two, as well as cutting speed to flank wear. From the geometrical point of view, depth of cut has no direct influence on surface roughness because the height and form of roughness profile are independent of depth of cut. Its indirect influence is through the forming of BUE, chip deformation, cutting temperature, vibration etc. Depth of cut has also a minor effect on the tool wear, but sometimes in practice it is inversely proportional to the tool wear, i.e. by decreasing the depth of cut the tool wear increases. This is explained using the theory of dislocations. Namely, in smaller volume of material, there are smaller numbers of errors in its crystal lattice, causing the material is homogeneous, and thus difficult to machine.

Table 4. Values obtained by regression analysis and neural network models

\begin{tabular}{|c|c|c|c|c|c|}
\hline \multirow{2}{*}{$\begin{array}{l}\text { Exp. } \\
\text { Num. }\end{array}$} & \multicolumn{5}{|c|}{ Regression } \\
\hline & $\begin{array}{c}R a \\
{[\mu \mathrm{m}]}\end{array}$ & $\begin{array}{l}V B_{\max } \\
{[\mu \mathrm{m}]}\end{array}$ & $\begin{array}{l}F X \\
{[\mathrm{~N}]}\end{array}$ & $\begin{array}{l}F y \\
{[\mathrm{~N}]}\end{array}$ & $\begin{array}{l}F z \\
{[\mathrm{~N}]}\end{array}$ \\
\hline $21^{*}$ & 0.66 & 59.2 & 167.5 & 131.2 & 39.4 \\
\hline $23^{*}$ & 0.79 & 54.6 & 193.5 & 143.5 & 40.8 \\
\hline $27^{*}$ & 1.01 & 48.5 & 204.8 & 141.8 & 43.9 \\
\hline $28 *$ & 0.62 & 37.0 & 178.3 & 135.1 & 37.9 \\
\hline $30 *$ & 1.43 & 67.2 & 186.7 & 140.8 & 41.1 \\
\hline $31^{*}$ & 0.65 & 61.1 & 191.3 & 127.8 & 36.4 \\
\hline $32 *$ & 0.61 & 36.2 & 180.2 & 136.2 & 37.9 \\
\hline $33^{*}$ & 1.17 & 51.1 & 242.1 & 165.1 & 47.5 \\
\hline \multirow{2}{*}{$\begin{array}{l}\text { Exp. } \\
\text { Num. }\end{array}$} & \multicolumn{5}{|c|}{ Neural network } \\
\hline & $\begin{array}{c}R a \\
{[\mu \mathrm{m}]}\end{array}$ & $\begin{array}{l}V B_{\max } \\
{[\mu \mathrm{m}]}\end{array}$ & $\begin{array}{l}F x \\
{[\mathrm{~N}]}\end{array}$ & $\begin{array}{l}F y \\
{[\mathrm{~N}]}\end{array}$ & $\begin{array}{l}F z \\
{[\mathrm{~N}]}\end{array}$ \\
\hline $21^{*}$ & 0.82 & 57.9 & 187.4 & 137.9 & 42.1 \\
\hline $23^{*}$ & 0.91 & 55.3 & 200.5 & 148.5 & 43.4 \\
\hline $27^{*}$ & 1.03 & 54.2 & 200.5 & 142.9 & 45.5 \\
\hline $28^{*}$ & 0.67 & 44.6 & 180.9 & 137.8 & 39.8 \\
\hline $30 *$ & 1.03 & 63.0 & 204.4 & 147.4 & 44.4 \\
\hline $31^{*}$ & 0.70 & 63.5 & 190.7 & 132.3 & 38.2 \\
\hline $32^{*}$ & 0.66 & 43.5 & 183.2 & 138.3 & 39.9 \\
\hline $33^{*}$ & 1.30 & 56.7 & 252.2 & 179.9 & 51.1 \\
\hline
\end{tabular}

Table 5. Testing the models capability for prediction of surface roughness, tool wear and cutting force

\begin{tabular}{|c|c|c|c|c|c|}
\hline \multirow{2}{*}{$\begin{array}{l}\text { Exp. } \\
\text { Numb. }\end{array}$} & \multicolumn{5}{|c|}{ Relative error using regression [\%] } \\
\hline & $\begin{array}{c}R a \\
{[\mu \mathrm{m}]}\end{array}$ & $\begin{array}{l}V B_{\max } \\
{[\mu \mathrm{m}]}\end{array}$ & $\begin{array}{l}F x \\
{[\mathrm{~N}]}\end{array}$ & $\begin{array}{l}\mathrm{Fy} \\
{[\mathrm{N}]}\end{array}$ & $\begin{array}{l}F z \\
{[\mathrm{~N}]}\end{array}$ \\
\hline $1^{*}$ & 16.46 & 2.07 & 4.80 & 3.52 & 6.25 \\
\hline $3^{*}$ & 5.95 & 5.00 & 3.25 & 3.01 & 9.39 \\
\hline $7^{*}$ & 8.18 & 11.82 & 0.56 & 0.81 & 8.40 \\
\hline $8^{*}$ & 5.78 & 9.76 & 2.05 & 0.05 & 7.50 \\
\hline $10^{*}$ & 10.68 & 5.00 & 4.26 & 5.53 & 7.71 \\
\hline $11^{*}$ & 2.99 & 0.16 & 0.17 & 4.62 & 10.88 \\
\hline $12^{*}$ & 6.15 & 9.50 & 8.55 & 4.76 & 9.67 \\
\hline $13^{*}$ & 16.43 & 10.35 & 3.58 & 3.51 & 8.69 \\
\hline \multirow[t]{2}{*}{ Average } & 9.08 & 6.71 & 3.40 & 3.23 & 8.56 \\
\hline & \multicolumn{5}{|c|}{ Total average relative error: $6.19 \%$} \\
\hline \multirow{2}{*}{$\begin{array}{l}\text { Exp. } \\
\text { Numb. }\end{array}$} & \multicolumn{5}{|c|}{ Relative error using neural network (\%) } \\
\hline & $\begin{array}{c}R a \\
{[\mu \mathrm{m}]}\end{array}$ & $\begin{array}{l}V B_{\max } \\
{[\mu \mathrm{m}]}\end{array}$ & $\begin{array}{l}F x \\
{[\mathrm{~N}]}\end{array}$ & $\begin{array}{l}F y \\
{[N]}\end{array}$ & $\begin{array}{l}F z \\
{[\mathrm{~N}]}\end{array}$ \\
\hline $1^{*}$ & 3.49 & 0.17 & 6.50 & 1,39 & 0.12 \\
\hline $3^{*}$ & 8.61 & 6.35 & 0.26 & 0.36 & 3.65 \\
\hline $7^{*}$ & 6.52 & 1.45 & 2.66 & 0.06 & 5.94 \\
\hline $8^{*}$ & 1.16 & 8.78 & 0.57 & 2.05 & 2.81 \\
\hline $10^{*}$ & 20.15 & 1.56 & 4.85 & 1.08 & 0.28 \\
\hline $11^{\star}$ & 3.79 & 4.10 & 0.16 & 1.29 & 6.37 \\
\hline $12^{*}$ & 2.23 & 8.75 & 6.99 & 3.28 & 4.81 \\
\hline $13^{*}$ & 7.19 & 0.53 & 0.47 & 5.25 & 1.71 \\
\hline \multirow[t]{2}{*}{ Average } & 6.64 & 3.96 & 2.81 & 1.84 & 3.21 \\
\hline & \multicolumn{5}{|c|}{ Total average relative error: $3.35 \%$} \\
\hline
\end{tabular}

Figs. 9 to 11 show the results obtained from both models in the form of graphical representation for the $x, y, z$ components of cutting force and its dependence on depth of cut and feed per tooth. Cutting speed has been kept constant at $130 \mathrm{~m} / \mathrm{min}$. It can be seen that the RA method predicts that the cutting force components depend almost linearly on both, depth of cut and feed per tooth. In graphical representations 
of the RBF method nonlinearity can be seen, which better describes the real state of the milling process. The minimum values of cutting force components are achieved when feed per tooth and depth of cut nearly reach their minimum values.

Increasing the cutting speed increases the angle of inclination of the plane shear layer separated materials, and reduces the length of the shear plane at constant shear strength. The force required for deformation of the material is then reduced. At low cutting speeds, the coefficient of friction increases, which is another reason for increased force. On the size of the cutting force, at the beginning of the process only the processing parameters are affected. During machining, cutting tool changes its properties because of tool wear. The cutting force at any point is equal to the initial cutting force plus the increment of the cutting force. This increment is different for different machining parameters.

In order to test which modeling method gives a better prediction, a relative error of deviations from measured values has been calculated. Validation of both models was performed with the testing data set that had not been used in the training process. Relative errors obtained using RA and RBF methodologies have been compared, and the results of testing are presented in Table 5. The results from Table 5 indicate that the RBF model offers the best prediction capability with total average relative error of $3.35 \%$.

\section{CONCLUSIONS}

The purpose of this study is the research of possibility of surface roughness, tool wear and cutting force component modeling to collect the information needed for effective machining planning as part of off-line process control. The influences of the cutting speed, the feed per tooth and the depth of cut on surface roughness, tool wear and cutting forces in the face milling process have been examined in the study, and in order to model dependency between those parameters, regression analysis and neural network methodology were used. Regarding the results, both methodologies are found to be capable of accurate predictions of the surface roughness, tool wear and cutting force components, although neural network models give somewhat better predictions, with approximate relative error of $3.35 \%$. The research has shown that when the training data set is relatively small (as in the study) neural network models are comparable with the RA methodology and can also offer even better results. More accurate predictions ultimately improve off-line process control resulting in significant reduction of machining cost.

Nevertheless, despite years of research and a multitude of success stories in the laboratory, only a small amount of modern technology has been transferred to production. Therefore, off-line process control as an approach that demonstrates its capabilities to be applied in practice and easily integrated in existing conditions still represents the key for successful machining and also the bridge between machining research and the production.

\section{REFERENCES}

[1] Furness, R.J., Ulsoy, A.G., Wu, C.L. (1996). Feed, speed, and torque controllers for drilling. ASME Journal for Manufacturing Scientists and Engineers, vol. 118, p. 2-9.

[2] Landers, R.G., Usloy, A.G., Furness, R.J. (2002). Process monitoring and control of machining operations. Mechanical Systems Design Handbook. CRC Press LLC, p. 85-119.

[3] Lu, C. (2008). Study on prediction of surface quality in machining process. Journal of Materials Processing Technology, vol. 205, no. 1-3, p. 439-450, DOI:10.1016/j.jmatprotec.2007.11.270.

[4] Bajić, D., Belaić, A. (2006). Mathematical modelling of surface roughness in milling process. Proceedings of the $1^{\text {st }}$ International Scientific Conference on Production Engineering (ISC), p. 109-115.

[5] Oktem, H., Erzurumlu, T., Kurtaran, H. (2005). Application of response surface methodology in the optimization of cutting conditions for surface roughness. Journal of Materials Processing Technology, vol. 170, p. 11-16, DOI:10.1016/j.jmatprotec.2005.04.096.

[6] Ezugvu, E.O., Arthur, S.J., Hines E.L. (1995). Tool-wear prediction using artificial neural networks. Journal of Materials Processing Technology, vol. 49, no. 3-4, p. 255-264, DOI:10.1016/0924-0136(94)01351-Z.

[7] Benardos, P.G., Vosniakos, G.C. (2002). Prediction of surface roughness in $\mathrm{CNC}$ face milling using neural networks and Taguchi's design of experiments. Robotics and Computer-Integrated Manufacturing, vol. 18, no.5, p. 343-354, DOI:10.1016/S0736-5845(02)00005-4.

[8] Klančnik, S., Balič, J., Čuš, F. (2010) Intelligent prediction of milling strategy using neural networks. Control and Cybernetics, vol. 39, no. 1, p. 9-22.

[9] Dong, J., Subrahmanyam, K.V.R., Wong, Y.S., Hong, G.S., Mohanty, A.R. (2006). Bayesian-inferencebased neural networks for tool wear estimation. The International Journal of Advanced Manufacturing Technology, vol. 30, no. 9-10, p. 797-807, DOI:10.1007/ s00170-005-0124-8.

[10] Hsueh, Y.W., Yang, C.Y. (2009). Tool breakage diagnosis in face milling by support vector machine. Journal of Materials Processing Technology, 
vol.209, no. 1, p. 145-152, DOI:10.1016/j. jmatprotec.2008.01.033.

[11] Čuš, F., Župerl, U. (2011). Real-time cutting tool condition monitoring in milling. Strojniški vestnik Journal of Mechanical Engineering, vol. 57, no. 2, p. 142-150, DOI:10.5545/sv-jme.2010.079.

[12] Korošec, M., Balič, J., Kopač, J. (2005). Neural network based manufacturability evaluation of free form machining. International Journal of Machine Tools \& Manufacture, vol. 45, no. 1, p. 13-20, DOI:10.1016/j.ijmachtools.2004.06.022.

[13] Özel, T., Karpat, Y. (2005). Predictive modeling of surface roughness and tool wear in hard turning using regression and neural networks. International Journal of Machine Tools \& Manufacture, vol.45, no.4-5, p. 467-479, DOI:10.1016/j.ijmachtools.2004.09.007.

[14] Benardos, P.G., Vosniakos, G.C. (2003). Prediction surface roughness in machining: a review. International Journal of Machine Tools \& Manufacture, vol. 43, no. 8, p. 833-844. DOI:10.1016/S0890-6955(03)00059-2.
[15] Roy, S.S. (2010). Modelling of tool life, torque and thrust force in drilling: a neuro-fuzzy approach. International Journal of Simulation Modelling, vol. 9, no. 2, p. 74-85, DOI: 10.2507/IJSIMM09(2)2.149.

[16] Yan, J., Murakami, Y., Davim, J.P. (2009). Tool Design, Tool Wear and Tool Life. Cheng, K. (ed.) Machining Dynamics: Fundamentals, Application and Practice, Springer, London, p. 133-138.

[17] Chaari, R., Abdennadher, M., Louati, J., Haddar, M. (2011). Modelling of the 3D machining geometric defects accounting for workpiece vibratory behaviour. International Journal of Simulation Modelling, vol. 10, no.2, p. 66-67, DOI: 10.2507/IJSIMM10(2)2.173.

[18] Montgomery, D.C. (2001). Design and analysis of experiments, John Wiley \& Sons, New York.

[19] Novaković, B., Majetić, D., Široki, M. (1998). Artificial neural network. University of Zagreb, Zagreb.

[20] Beale, M.H., Hagan, M.T., Demuth, H.B. (2010). Neural Network Toolbox 7: User's Guide, The Mathworks, Natick. 